\title{
Erratum to: Femoroacetabular impingement: a review of diagnosis and management
}

\author{
Purnajyoti Banerjee • Christopher R. Mclean
}

Published online: 1 August 2012

(C) Springer Science+Business Media, LLC 2012

Erratum to: Curr Rev Musculoskelet Med 2011 4(1):23-32

DOI 10.1007/s12178-011-9073-z

Banerjee P, Mclean CR: Femoroacetabular impingement: a review of diagnosis and management. Curr Rev Musculoskelet Med 2011, 4(1): 23-32.

This article was published in the March 2011 issue of Current Reviews in Musculoskeletal Medicine (Volume 4, Issue 1).

Figure $2 b$, Figure $4 b$, and Table 1 should be credited, with permission, to Tannast et al., Femoroacetabular impingement: radiographic diagnosis - what the radiologist should know. AJR 2007 Jun;188(6):1540-52.

The authors would also like to acknowledge and thank Mr. RE Field (FRCS Orth) and Mr. P Singh (FRCS Orth) consultant orthopaedic surgeons at Elective Orthopaedic Centre Epsom, who helped with the other radiographs used in this paper.

The online version of the original article can be found at http://dx.doi.org/ 10.1007/s12178-011-9073-z.

P. Banerjee $(\bowtie) \cdot$ C. R. Mclean

South West London Elective Orthopaedic Centre,

Research \& Education Unit, Epsom General Hospital,

Dorking Road,

London, Surrey KT18 7EG, UK

e-mail: banerjee_purnajyoti@yahoo.co.in 